\title{
Comparative study for effectiveness of preemptive analgesia on postoperative pain and swelling following gingivectomy
}

\author{
Amit Kumar Srivastava ${ }^{1 *}$, Sumant Kumar Singh ${ }^{2}$, Manoj Kumar ${ }^{3}$, Arpita Srivastava ${ }^{4}$, Pranshu Kumar Pathak ${ }^{5}$ \\ ${ }^{\mathbf{1}}$ Associate Professor, ${ }^{\mathbf{2}}$ Assistant Professor, ${ }^{\mathbf{3}}$ Professor, ${ }^{\mathbf{4}}$ Lecturer, ${ }^{\mathbf{5}}$ Senior Resident, Dept. of Dental Surgery, ${ }^{\mathbf{1 - 3 , 5}}$ Baba Raghav Das Medical \\ College, Gorakhpur, Uttar Pradesh, ${ }^{4}$ Purvanchal Institute of Dental Sciences, Gorakhpur, Uttar Pradesh India \\ *Corresponding Author: Amit Kumar Srivastava \\ Email: amit.radc@gmail.com
}

\begin{abstract}
Introduction: Prevention of postoperative pain can be achieved by effective blockade of noxious stimuli generated during surgery that is after central sensitization. Preventive analgesia or antinociceptive treatment started before surgery in order to prevent central sensitization and limit the subsequent pain experience. ${ }^{1}$

Aim and Objective: The aim of the study was to evaluate the role of NSAIDs as preemptive analgesia in controlling pain and swelling after gingivectomy.

Materials and Methods: total of 60 patients were randomly divided into 3 groups, Group A: Tab Aceclofenac $100 \mathrm{mg}$ given 30 minutes before gingivectomy, Group B: Tab Ibuprofen 400mg and in Group C: Placebo given to the patients 30 minutes before gingivectomy procedure. Pain intensity were recorded at $6 \mathrm{hr}, 12 \mathrm{hrs}, 24 \mathrm{hrs}$, day 2 and day3 post gingivectomy. Swelling and No. of rescue analgesic taken by the patient recorded at day 1, day 2 and day 3 after gingivectomy.

Result: The result showed that postoperative pain and swelling reduction was better with Aceclofenac followed by Ibuprofen then Placebo. The distribution of pain reduction was statistically significant at $6 \mathrm{hr}$ postgingivectomy.

Conclusion: A preoperative single dose of anti-inflammatory drugs (NSAIDs) can regulate the release of inflammatory mediators and reduce the amount of pain and swelling during postoperative period.
\end{abstract}

Keywords: Nonsteroidal anti-inflammatory drugs, Chemical mediators, Gingivectomy, Preemptive analgesia, Visual analog scale.

\section{Introduction}

Gingivectomy is one of the most common periodontal surgical procedure for the treatment of gingival enlargement. Most of the patients complaint pain following gingivectomy. This pain may be produced either by central or peripheral sensitization. Peripheral sensitization is the reduction in the threshold and increased responsiveness of nociceptive afferent peripheral nerve terminals. Peripheral nociceptors becomes more responsive with repeated application of noxious stimulus. ${ }^{2,3}$ Following peripheral tissue injury, chemical changes can occurs within the CNS. A variety of neurotransmitters are released of which are the most important is substance P. Substance P induces the release of excitatory amino acids such as glutamate and aspartate involved in the increased excitability of N-methyl D aspartate(NMDA) receptor site within the spinal cord. It has been proposed that NMDA receptor sites by excitatory amino acids enhances depolarization, making the neurons more responsive and this leads to amplification and increased duration of pain. ${ }^{4}$ Noxious stimuli causing tissue damage can cause hypersensitivity, hyperalgesia is attributed to combination of peripheral sensitization associated with the lowered threshold of nociceptors and central sensitization linked to the increased excitability of central nervous system. ${ }^{5}$ The aim of preemptive analgesia is to minimize or prevent onset of peripheral and central sensitization by employing various interventions at different stages of pain pathways.

\section{Materials and Methods}

This double blind, active control, randomized clinical study was carried out in out patient dept. of Periodontics, Purvanchal Institute of Dental Sciences and Dental Surgery Department, B.R.D. Medical College, Gorakhpur. All patients were explained about study and an informed consent was obtained from them. Ethical committee clearance was obtained before starting of the study.

\section{Study design}

Patient with both sexes, age group ranging between 18-45 years with good general health and oral hygiene habit were selected for the study. Subject were not taken any systemic antibiotic since last 6 months before the commencement of the study. Patient with moderate to advanced periodontal destruction with suprabony pocket more than $5 \mathrm{~mm}$ in depth or gingival enlargement in which the bottom of the pocket not apical to the mucogingival junction were included in the study. The patients were divided into three groups, Group A: 20 patients were given Tab Aceclofenac $(100 \mathrm{mg})$ orally, Group B: Tab Ibuprofen (400mg) orally and in Group C: Placebo drug orally administered 30 minutes before gingivectomy. A definite set of questionnaires are given to the patients to fill at $6 \mathrm{hrs}, 12 \mathrm{hrs}, 24 \mathrm{hrs}$, day 2 and day 3 after gingivectomy to assess the patients experience of pain and discomfort postoperatively.

\section{Presurgical consideration}

All patients were subjected to a thorough initial mouth preparation, oral hygiene instructions, scaling, root planning and polishing etc. at least one week before gingivectomy to 
minimize gingival inflammation so that identical clinical pictures existing in all the surgical areas.

\section{Surgical procedure}

Following administration of local anaesthesia (Lignocaine $\mathrm{HCl} 2 \%$ with Adrenalin 1:100000), pocket depth marked with the help of pocket marker facially. External bevel gingivectomy was performed as described by Goldman. ${ }^{6}$

\section{Postsurgical consideration}

Patients were under proper antibiotic coverage and advised to take 1 tab Acetaminophen (Paracetamol) $650 \mathrm{mg}$ as a rescue medication. Patients were recalled at day 1 , day 2 and on day 3 postoperatively. At each of recall visit oral hygiene was assessed and oral hygiene instructions were reinforced. All postoperative pictures were recorded and compared with just before surgical intervention on a carefully prepared history sheet utilizing same parameters.

\section{Parameters studied}

1) Plaque index, 2) Gingival index, 3) Postoperative pain, 4) No. of analgesic taken 5) Postoperative swelling.

\section{Postoperative pain}

The visual analog scale (VAS) was used to evaluate the pain experienced by the patients. It consist of $0-10 \mathrm{~cm}$ scale with $1 \mathrm{~cm}$ graduations. The level no pain was given the position zero and the level most severe pain was given the position ten. Pain scoring: Score 0-No pain, Score 1-Mild pain, Score 2-Moderate and Score 3-Severe.

\section{No. of analgesic (Acetaminophen 650mg) tablets taken by the patient on postoperative days}

Tab Acetaminophen 650mg was prescribed as rescue medication for pain relief in all the patients. They were strictly instructed to take analgesic drugs whenever the subject suffered from pain and could repeat the dose every 6 hr. The pain score and no. of analgesics taken by the patients were recorded at every recall visits.

\section{Postoperative swelling}

At every postsurgical recall visit operated areas were assessed for swelling by visual scoring system. Swelling scoring: Score 0-none (No swelling), Score 1-Mild, Score 2Moderate, Score 3-Severe

\section{Statistical analysis}

Statistical analysis employed to compare the study results using a computer software (Epi info software). To determine the differences in the distribution of various parameters between groups one way analysis of variance (ANOVA) test were utilized. The level of $\mathrm{P}<0.05$ was considered significant.

\section{Results and Analysis}

A total of 60 patients with gingival enlargement were selected for external bevel gingivectomy. A number of clinical parameters namely pain at $6 \mathrm{hr}, 12 \mathrm{hr}, 24 \mathrm{hrs}$, day 2 and at day 3 postgingivectomy evaluated. No. of analgesic (Acetaminophen $650 \mathrm{mg}$ ) taken by the patient, swelling, plaque index and gingival index were evaluated at day 1 , day 2 and at day 3 postgingivectomy. Data obtained were statistically analysed. At $6 \mathrm{hr}$ postgingivectomy the mean value for Group A (Aceclofenac), Group B (Ibuprofen) and Group C (Placebo) were 1.6, 1.85 and 2.05 respectively. This shows that with Aceclofenac patients experienced comparatively less pain as compared to Ibuprofen and Placebo. The distribution of pain reduction was statistically significant between these three group at $6 \mathrm{hr}$ postgingivectomy. At $12 \mathrm{hrs}$, 24hrs, day 2 and day 3 postgingivectomy pain reduction was more with the Aceclofenac followed by Ibuprofen and least with the Placebo, but the result was statistically insignificant. (Table 1)

No. of rescue medicine (Acetaminophen 650mg) taken by the patients was more with the Placebo group and least with the Aceclofenac group but it was statistically insignificant. (Table 2)

At day 1 and day 2 the swelling was almost same in all three groups but at day3 it was noted that swelling was least with Aceclofenac followed by Ibuprofen then Placebo but the $p$ value was statistically insignificant. (Table 3 )

\section{Discussion}

Preemptive analgesia is defined as an antinociceptive treatment that prevents establishment of altered central processing of afferent input from injury. ${ }^{7}$ Owing to this protective effect on nociceptive system, preemptive analgesia has potential to be more effective than similar analgesic treatment started after surgical procedure. As a consequence preemptive analgesia can reduce immediate postoperative pain and also prevent the development of chronic pain by decreasing the altered central sensory processing. ${ }^{8}$ Many studies have confirmed the positive effect of preemptive analgesia such as administration of NSAIDs (Nonsteroidal anti-inflammatory drugs), SAIDs (steroidal anti-inflammatory drugs), Opiod analgesic or presurgical administration of Ketamine as an NMDA(Nmethyl-D-aspartate) antagonist and peritoneal infusion of long acting local anaesthetics through abdominal incision. For dental pain, NSAIDs are one of the most frequently taken analgesic medication. NSAIDs inhibits inflammation and induce analgesia by inhibiting the activity of cyclooxygenase (COX). Two forms of COX enzymes have been identified COX1 and COX2.COX1 enzyme is present in all tissue and responsible for synthesizing prostanoids that have a cytoprotective function.COX1 enzyme regulates normal activities in stomach, kidney and platelets.COX2 enzymes normally are not present in the tissues and come into play when tissue injury and inflammation occur. Thus NSAIDs exerts their analgesic, antipyretic and antiinflammatory action by central as well as peripheral mechanism. Aceclofenac (NSAIDs) is predominantly a potent inhibitor of $\mathrm{COX} 2$ which is used for pain management. It share structural similarity with another NSAIDs Diclofenac. The therapeutic index of aceclofenac 
was reported to be four times greater than that of Diclofenac. Chunduri et al 2013 studied the preemptive effect of Aceclofenac and diclofenac in third molar surgery observed reduction in postoperative pain when administered NSAIDs preoperatively. ${ }^{9,10}$

Ibuprofen is a NSAIDs that is used for treating pain, fever and inflammation. Compared to other NSAIDs it have fewer side effects such as gastrointestinal bleeding. It works by inhibiting production of prostaglandin by decreasing the activity of cyclooxygenase. Ibuprofen is a nonselective COX inhibitor, in that it inhibits two isoforms of cyclooxygenase $\mathrm{COX} 1$ and $\mathrm{COX} 2$. Its action mainly through inhibition of COX2.

Pillati et al 2006 in mucoperiosteal flap surgery ${ }^{11}$ and in crown lengthening Peres et al found no significant difference for the pain intensity when steroidal antiinflammatory drugs and NSAIDs were compared as preemptive medications. ${ }^{11,12}$ Steffens et al (2010) also showed no significant difference for pain between Dexamethasone $8 \mathrm{mg}$ and Celecoxib $120 \mathrm{mg}$ group, this was also true for mucoperiosteal flap surgery. ${ }^{13}$ On the other hand Mehra et al in 2013 compared different pharmacological regimen using SAIDs and NSAIDs and demonstrated that the NSAIDs (Ibuprofen) produced an increased reduction of pain. ${ }^{14}$ They observed that patients receiving 600mg of Ibuprofen preemptive and postoperative for a week reported increased effectiveness in reducing PGE2 level in urine and saliva compared to Dexamethasone alone after the removal of impacted lower third molar.

Placebo used in this study had not any antiinflammatory characteristics as those of Aceclofenac and Ibuprofen so it is not expected to influence any inflammatory response. Therefore placebo group showed least reduction of postoperative pain.

Table 1: Shows postgingivectomy pain at 6hrs, $12 \mathrm{hrs}, 24 \mathrm{hrs}$, day 2 and day 3 in Aceclofenac, ibuprofen and placebo groups

\begin{tabular}{|c|c|c|c|c|}
\hline \multirow[t]{2}{*}{ Groups } & \multicolumn{4}{|c|}{ Postoperative pain at 6 hours } \\
\hline & $\mathbf{N}$ & Mean & Std. Deviation & Significance \\
\hline Aceclofenac (Group A) & 20 & 1.6 & 0.68 & \multirow[t]{3}{*}{$<0.05$} \\
\hline Ibuprofen (Group B) & 20 & 1.85 & 0.37 & \\
\hline \multirow[t]{3}{*}{ Placebo (Group C) } & 20 & 2.05 & 0.39 & \\
\hline & & \multicolumn{3}{|c|}{ Postoperative pain at 12 hours } \\
\hline & $\mathrm{N}$ & Mean & Std. Deviation & Significance \\
\hline Aceclofenac (Group A) & 20 & 1.0 & 0.79 & $>0.05$ \\
\hline Ibuprofen (Group B) & 20 & 1.4 & 0.60 & \\
\hline \multirow[t]{3}{*}{ Placebo (Group C) } & 20 & 1.55 & 0.51 & \\
\hline & & \multicolumn{3}{|c|}{ Postoperative pain at 24 hours } \\
\hline & $\mathrm{N}$ & Mean & Std. Deviation & Significance \\
\hline Aceclofenac (Group A) & 20 & 0.6 & 0.51 & $>0.05$ \\
\hline Ibuprofen (Group B) & 20 & 0.6 & 0.60 & \\
\hline \multirow[t]{3}{*}{ Placebo (Group C) } & 20 & 1.15 & 0.49 & \\
\hline & & \multicolumn{3}{|c|}{ Postoperative pain at day 2} \\
\hline & $\mathrm{N}$ & Mean & Std. Deviation & Significance \\
\hline Aceclofenac (Group A) & 20 & 0.4 & 0.50 & $>0.05$ \\
\hline Ibuprofen (Group B) & 20 & 0.55 & 0.51 & \\
\hline \multirow[t]{3}{*}{ Placebo (Group C) } & 20 & 0.75 & 0.44 & \\
\hline & & \multicolumn{3}{|c|}{ Postoperative pain at day 3} \\
\hline & $\mathrm{N}$ & Mean & Std. Deviation & Significance \\
\hline Aceclofenac (Group A) & 20 & 0.15 & 0.37 & $>0.05$ \\
\hline Ibuprofen (Group B) & 20 & 0.35 & 0.49 & \\
\hline Placebo (Group C) & 20 & 0.55 & 0.51 & \\
\hline
\end{tabular}

Table 2: Shows number of analgesic taken by the patients at day1, day2 and day3 in Aceclofenac, ibuprofen and placebo groups after gingivectomy

\begin{tabular}{|c|c|c|c|c|}
\hline \multirow[t]{2}{*}{ Groups } & & \multicolumn{3}{|c|}{ No. of analgesics at day 1} \\
\hline & $\mathbf{N}$ & Mean & Std. Deviation & Significance \\
\hline Aceclofenac (Group A) & 20 & 2.3 & 0.47 & \multirow[t]{3}{*}{$>0.05$} \\
\hline Ibuprofen (Group B) & 20 & 2.4 & 0.50 & \\
\hline \multirow[t]{3}{*}{ Placebo (Group C) } & 20 & 2.55 & 0.51 & \\
\hline & & \multicolumn{3}{|c|}{ No. of analgesics at day 2} \\
\hline & $\mathbf{N}$ & Mean & Std. Deviation & Significance \\
\hline Aceclofenac (Group A) & 20 & 1.65 & 0.49 & $>0.05$ \\
\hline Ibuprofen (Group B) & 20 & 1.8 & 0.52 & \\
\hline
\end{tabular}




\begin{tabular}{|l|c|c|c|c|}
\hline Placebo (Group C) & 20 & 1.95 & 0.51 & \\
\hline & & \multicolumn{3}{|c|}{ No. of analgesics at day 3 } \\
\cline { 2 - 5 } & $\mathbf{N}$ & Mean & Std. Deviation & Significance \\
\hline Aceclofenac (Group A) & 20 & 0.55 & 0.51 & $>0.05$ \\
\hline Ibuprofen (Group B) & 20 & 1.35 & 0.49 & \\
\hline Placebo (Group C) & 20 & 1.5 & 0.51 & \\
\hline
\end{tabular}

Table 3: Shows postgingivectomy swelling at day 1, day and day 3 in Aceclofenac, ibuprofen and placebo groups

\begin{tabular}{|c|c|c|c|c|}
\hline \multirow[t]{2}{*}{ Groups } & & \multicolumn{3}{|c|}{ Postoperative swelling at day 1} \\
\hline & $\mathbf{N}$ & Mean & Std. Deviation & Significance \\
\hline Aceclofenac (Group A) & 20 & 1.5 & 0.51 & $>0.05$ \\
\hline Ibuprofen (Group B) & 20 & 1.75 & 0.44 & \\
\hline \multirow[t]{3}{*}{ Placebo (Group C) } & 20 & 1.9 & 0.55 & \\
\hline & & \multicolumn{3}{|c|}{ Postoperative swelling at day 2} \\
\hline & $\mathbf{N}$ & Mean & Std. Deviation & Significance \\
\hline Aceclofenac (Group A) & 20 & 1.75 & 0.44 & $>0.05$ \\
\hline Ibuprofen (Group B) & 20 & 1.65 & 0.49 & \\
\hline \multirow[t]{3}{*}{ Placebo (Group C) } & 20 & 1.85 & 0.37 & \\
\hline & & \multicolumn{3}{|c|}{ Postoperative swelling at day 3} \\
\hline & $\mathbf{N}$ & Mean & Std. Deviation & Significance \\
\hline Aceclofenac (Group A) & 20 & 0.5 & 0.51 & $>0.05$ \\
\hline Ibuprofen (Group B) & 20 & 1.3 & 0.66 & \\
\hline Placebo (Group C) & 20 & 1.4 & 0.60 & \\
\hline
\end{tabular}

\section{Conclusion}

Aceclofenac was better in reduction of pain and swelling after gingivectomy procedure followed by Ibuprofen then Placebo when administered 30 minutes preoperatively. To avoid exaggerated claim and drawing a definite conclusion regarding efficacy of preemptive analgesia further study involving higher number of samples are warranted.

\section{Source of funding}

None.

\section{Conflict of interest}

None.

\section{References}

1. Kelly DJ, Ahmad M., Brull SJ. Preemptive analgesia II. Can J Anaesth 2001;48:1000-10.

2. Pochapski MT, Santos FA, de Andrade ED, Sydney GB. Effect of pretreatment dexamethasone on postendodontic pain. Oral Surg, Oral Med, Oral Pathol, Oral Radiol Endod 2009;108 (5):790-5.

3. Kelly DJ, Ahmad M. Brull SJ. Preemptive analgesia II: recent advances and current trends. Can J Anaesth 2001;48(11):1091101.

4. Woolf CJ. An overview of the mechanisms of hyperalgesia. Pulm Pharmacol 1995;8(4-5):1979-84.

5. Woolf CJ. Evidence for a central component of post - injury pain hypersensitivity. Nat 1983;306:66-8.

6. Goldman HM. Gingivectomy. Oral Surg Oral Med Oral Pathol 1951;4:1136-57.

7. Igor K. Preemptive analgesia. Anaesthesiol 2000;93:1138-43.
8. Forsgren H, Heimdahl A, Johansson B, Krekmanov L. Effect of application of cold dressings on post operative course in oral surgery. Int J Oral Surg 1985;14:223-8.

9. Chunduri NS, Kollu T. Efficay of aceclofenac and diclofenac sodium for relief of postoperative pain after third molar surgery: Arandomized label comparative study. J Pharmacol Pharmacotherapeutics 2013;4(2):144.

10. Arslan SA, Tirnaksiz FA.A nonsteroidal anti-inflammatory drug: aceclofenac. FABA J Pharm Sci 2010;35(2):105-18.

11. Pellati GL. The use of celecoxib and dexamethasone for the prevention and control of postoperative pain after periodontal surgery. J Periodontol 2006;77:1809-14.

12. Peres MF. Steroidal and non-steroidal cyclooxygenase 2 inhibitor anti-inflammatory drug as preemptive medication in patient undergoing periodontal surgery. Br Dent $J$ 2012;23:621-8.

13. Mehra P, Reebye U. Efficacy of anti-inflammatory drugs in third molar surgery: a randomized clinical trial. Int J Oral Maxillofac Surg 2013;42:835-42.

14. Steffens JP, Santos FA, Sartori R. Preemptive dexamethasone and etoricoxib for pain and discomfort prevention after periodontal surgery: a double masked, crossover, controlled clinical trial. J Periodontol 2010;81:1153-60.

How to cite: Srivastava AK, Singh SK, Kumar M, Srivastava A, Pathak PK. Comparative study for effectiveness of preemptive analgesia on postoperative pain and swelling following gingivectomy. IP Int $J$ Periodontol Implantol 2020;5(1):25-8. 